ORIGINAL ARTICLE

\title{
Three year follow up of a self certification system for the assessment of fitness to dive in Scotland
}

\section{S Glen}

Br J Sports Med 2004;38:754-757. doi: 10.1136/bjsm.2003.008987

Background: The need for routine medical examinations of sport divers in the Scottish Sub-Aqua Club (Scot-SAC) was revised in March 2000, and a new system using a self administered screening questionnaire was developed to allow divers to be assessed when necessary by doctors with diving medicine experience.

Objective: To assess the effect of the new medical system on medical referee workload, diver exclusion rates, and diving incident frequency.

Methods: All divers were required to complete a questionnaire to screen for conditions that might affect fitness to dive. Divers answering "Yes" to any of the questions had their medical background assessed by a diving doctor, and, if necessary, received a clinical examination or investigation. The rate of diver exclusions based on the questionnaire response was recorded in conjunction with analysis of the incident reports.

Results: The number of forms requiring review by diving doctors increased from $1.2 \%$ to $5.7 \%(p<0.0001$, $95 \%$ confidence interval (Cl) -0.06 to -0.03 ) in the year after the introduction of the new medical system and gradually increased in subsequent years to $7.7 \%(\mathrm{p}<0.0001,95 \% \mathrm{Cl}-0.08$ to -0.05$)$. The number of divers failing to be certified fit to dive increased slightly from $0.7 \%$ to $1.0 \%$ after one year $(p=0.26$,

Correspondence to: Dr Glen, Department of Medicine, Stirling Royal Infirmary, Livilands, Stirling FK8 2AU,

Scotland, UK:

stephen.glen@

fvah.scot.nhs.uk

Accepted 6 October 2003 $95 \% \mathrm{Cl}-0.01$ to 0.00 ) and subsequently to $2.0 \%$ ( $p=0.0003,95 \% \mathrm{Cl} 0.02$ to -0.01 ) after three years. Most divers were certified fit to dive on the basis of the questionnaire alone, and only $0.9 \%$ required objective investigation (such as exercise testing or echocardiography). Analysis of the incidents during three years of follow up confirmed that no incident occurred because of an undetected pre-existing medical condition. Two incidents involved divers with hypertension, but both had received medical examinations and investigation based on their responses to the questionnaire.

Conclusion: The new self administered questionnaire system appears to be an effective screening tool for the detection of divers requiring detailed assessment by doctors with diving medicine experience.
U ntil March 2000, all divers belonging to the major UK sport diving organisations were required to have a medical examination to confirm their fitness to dive. These examinations were usually performed by general practitioners without specific diving medicine experience, and subsequent referrals were passed to the UK Sport Diving Medical Committee (UKSDMC) referee network. A recent study ${ }^{1}$ found that abnormalities were rarely detected during the screening clinical examination, and confirmed that the questionnaire was the most important component of the medical assessment and could be used to identify divers requiring further assessment by diving doctors. On the basis of a recommendation from the UKSDMC, the Scottish SubAqua Club (Scot-SAC) removed the need for routine medical examinations. This study reports the effects of the change of system.

There is no specific ethics committee responsible for ScotSAC, so the results of the initial study and the subsequent change in medical system were reviewed and approved by the national advisory committee, the UKSDMC. This committee also advises the British Sub-Aqua Club and the Sub-Aqua Association on diving medicine issues. The proposal from the UKSDMC to change the medical system was submitted to the Scot-SAC National Diving Council and approved at the Annual General Meeting in 2000. Scot-SAC is the governing body for diving in Scotland. The British Sub-Aqua Club and Sub-Aqua Association adopted the new medical system in June 2001 after approval at their respective annual general meetings.
Scot-SAC divers require a current certificate of fitness to dive for a valid membership, and from 1 March 2000 all new entrants and divers updating their medical certification were issued with a self administered medical questionnaire (table 1). This was designed by UKSDMC members and incorporates the results of the previous Scot-SAC study. ${ }^{1}$ The aim of the questionnaire was to detect underlying medical conditions relevant to dive fitness without causing spurious referrals. It was hoped to achieve a reasonable balance between sufficient sensitivity as a screening tool and specificity or positive predictive power.

\section{METHODS}

Scot-SAC medical forms and questionnaires are processed centrally, and all self administered questionnaires were checked by the Scot-SAC administrator. Forms containing positive answers to any of the questions were reviewed by the Scot-SAC medical advisor (SG) or by an approved UKSDMC referee in a minority of cases. Assessment of fitness to dive was based on the information available from the diver, the general practitioner, or hospital specialist, and from clinical assessment and objective investigation in some cases.

Scot-SAC has a voluntary incident reporting system encouraging divers and their supervising branch diving officers to notify the National Diving Committee. This often results in multiple reporting of the same incident, but it

Abbreviations: Scot-SAC, Scottish Sub-Aqua Club; UKSDMC, UK Sport Diving Medical Committee 
Table 1 UK Sport Diving Medical Committee self administered questionnaire

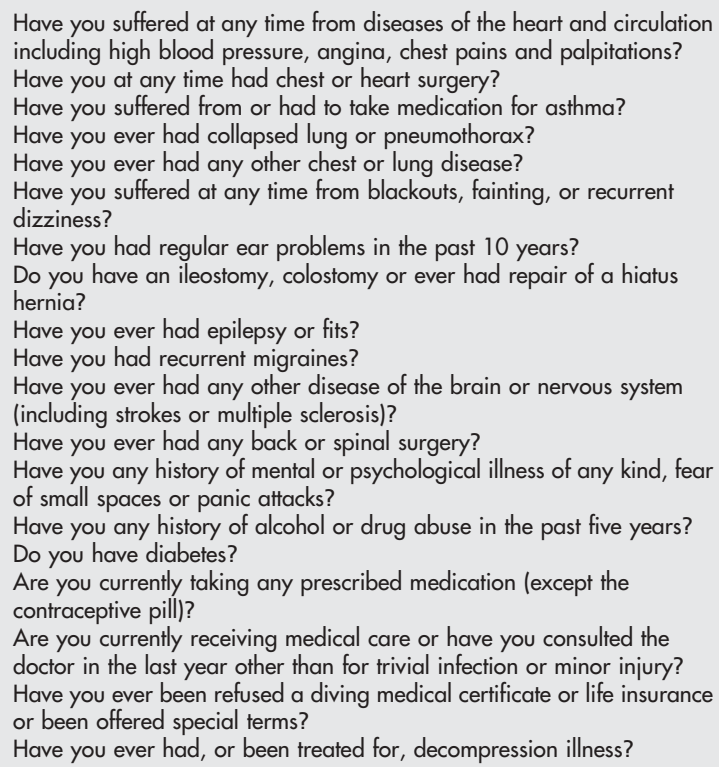

Are you currently taking any prescribed medication (except the contraceptive pill)?

Are you currently receiving medical care or have you consulted the doctor in the last year other than for trivial infection or minor injury? Have you ever been refused a diving medical certificate or life insurance or been offered special terms?

Have you ever had, or been treated for, decompression illness?

ensures that events do not pass without notice. Details of incidents are also sought in the medical form before a diver is allowed to return to active diving.

\section{Statistical analysis}

Statistical analysis is mainly descriptive, and all diver information was anonymised before analysis. Frequency and proportion comparisons were made using the $\chi^{2}$ test and calculation of $95 \%$ confidence intervals.

\section{RESULTS}

Table 2 shows the effects of the new medical system. The striking finding is an increase in the number of forms requiring review by a medical referee from $1.2 \%$ in 1999 to $5.7 \%$ in $2000(\mathrm{p}<0.0001,95 \%$ confidence interval (CI) -0.06 to -0.03$)$ and increasing subsequently to $7.7 \%$ in 2002 $(\mathrm{p}<0.0001,95 \%$ CI -0.08 to -0.05$)$ with a corresponding increase in the number of divers who could not be certified fit to dive from $0.7 \%$ in 1999 to $1.0 \%$ in 2000 ( $\mathrm{p}=0.26,95 \%$ CI -0.01 to 0.00$)$ and subsequently to $2.0 \%$ in 2002 ( $\mathrm{p}=$ $0.0003,95 \%$ CI -0.02 to -0.01 ).

Table 3 classifies the types of referral received from l March 2000 until 28 February 2003. The most common
Table 3 Classification of referrals in the new medical system

\begin{tabular}{|c|c|c|}
\hline System & Specific condition & Number \\
\hline \multirow[t]{7}{*}{ Cardiac } & Arrhythmia & 2 \\
\hline & $\begin{array}{l}\text { Atrial septal defect or patent foramen } \\
\text { ovale }\end{array}$ & 4 \\
\hline & $\begin{array}{l}\text { Coronary artery disease (including } \\
\text { myocardial infarction, bypass surgery, } \\
\text { and percutaneous intervention) }\end{array}$ & 8 \\
\hline & Hypertension & 39 \\
\hline & Hypotension & 2 \\
\hline & Pacemaker & 1 \\
\hline & Valvular heart disease or surgery & 3 \\
\hline \multirow{5}{*}{$\begin{array}{l}\text { Decompression } \\
\text { illness } \\
\text { Endocrine }\end{array}$} & Within limits & 29 \\
\hline & Outwith limits & 6 \\
\hline & Hypothyroidism (on thyroxine) & 7 \\
\hline & Insulin dependent diabetes mellitus & 6 \\
\hline & Non-insulin dependent diabetes & 1 \\
\hline \multirow[t]{4}{*}{ Ear, nose, throat } & Ear clearing difficulty & 8 \\
\hline & Hay fever or nasal polyp & 5 \\
\hline & Sinusitis & 1 \\
\hline & Perforated ear drum & 4 \\
\hline Eyes & Laser iridectomy & 1 \\
\hline \multirow[t]{7}{*}{ Gastrointestinal } & Colonic carcinoma & 5 \\
\hline & Colostomy & 1 \\
\hline & Crohn's disease & 3 \\
\hline & Diverticular disease & 1 \\
\hline & Hiatus hernia & 2 \\
\hline & Irritable bowel syndrome & 1 \\
\hline & Oesophageal stricture & 1 \\
\hline \multirow[t]{2}{*}{ General } & Various & 47 \\
\hline & Medication & 43 \\
\hline \multirow[t]{4}{*}{ Haematology } & Antithrombin III deficiency & 1 \\
\hline & Haemophilia & 1 \\
\hline & Polycythaemia & 1 \\
\hline & von Willebrand's disease & 1 \\
\hline \multirow[t]{7}{*}{ Neurology } & Cerebrovascular disease & 2 \\
\hline & Epilepsy & 7 \\
\hline & Erb's palsy & 1 \\
\hline & Head injury & 1 \\
\hline & Migraine & 11 \\
\hline & Multiple sclerosis & 1 \\
\hline & Subarachnoid haemorrhage & 1 \\
\hline \multirow[t]{2}{*}{ Orthopaedic } & $\begin{array}{l}\text { Spinal surgery or prolapsed } \\
\text { intervertebral disc }\end{array}$ & 13 \\
\hline & Joint surgery & 4 \\
\hline \multirow[t]{2}{*}{ Psychiatric } & Depression or anxiety & 18 \\
\hline & Claustrophobia & 3 \\
\hline \multirow[t]{2}{*}{ Renal } & Pyelonephritis & 1 \\
\hline & Proteinuria & 1 \\
\hline \multirow[t]{4}{*}{ Respiratory } & Asthma & 98 \\
\hline & Chronic obstructive pulmonary disease & 2 \\
\hline & Cystic fibrosis & 1 \\
\hline & Pneumothorax & 8 \\
\hline \multirow[t]{3}{*}{ Rheumatology } & Rheumatoid arthritis & 2 \\
\hline & Systemic lupus erythematosus & 1 \\
\hline & Raynaud's disease & 1 \\
\hline Vascular & Hereditary haemorrhagic telangiectasia & 1 \\
\hline Combined total & & 413 \\
\hline
\end{tabular}

Table 2 Effect of the new medical system (starting 1 March 2000)

\begin{tabular}{|c|c|c|c|c|c|c|}
\hline \multirow[b]{2}{*}{ Year } & \multicolumn{3}{|c|}{ Old medical system } & \multicolumn{3}{|c|}{ New medical system } \\
\hline & 1997 & 1998 & 1999 & 2000 & 2001 & 2002 \\
\hline Number of members & 1796 & 1809 & 1931 & 1896 & 1950 & 1896 \\
\hline $\begin{array}{l}\text { Number of forms requiring review by } \\
\text { medical referee }\end{array}$ & $10(0.6)$ & 23 (1.3) & $24(1.2)$ & $109(5.7)$ & $135(6.9)$ & $146(7.7)$ \\
\hline Passed without clinical assessment & $3(0.2)$ & $14(0.8)$ & $10(0.5)$ & $70(3.7)$ & $83(4.3)$ & $86(4.5)$ \\
\hline Passed after clinical assessment & $0(0.0)$ & $2(0.1)$ & $0(0.0)$ & $3(0.2)$ & $14(0.7)$ & $9(0.5)$ \\
\hline Passed after investigation & $2(0.1)$ & $1(0.1)$ & $1(0.1)$ & $17(0.9)$ & $9(0.5)$ & $13(0.7)$ \\
\hline Subtotal & $5(0.3)$ & $17(0.9)$ & $11(0.6)$ & $90(4.7)$ & $106(5.4)$ & $108(5.7)$ \\
\hline Failed outright based on form & $4(0.2)$ & $3(0.2)$ & $7(0.4)$ & $5(0.3)$ & $7(0.4)$ & $20(1.1)$ \\
\hline Declined assessment & $1(0.1)$ & $2(0.1)$ & $4(0.2)$ & $14(0.7)$ & $19(1.0)$ & $15(0.8)$ \\
\hline Failed after clinical assessment & $0(0.0)$ & $1(0.1)$ & $2(0.1)$ & $0(0.0)$ & $3(0.2)$ & $3(0.2)$ \\
\hline Subtotal & $5(0.3)$ & $6(0.3)$ & $13(0.7)$ & $19(1.0)$ & $29(1.5)$ & $38(2.0)$ \\
\hline
\end{tabular}


conditions described were asthma (23.7\% of referrals), medication queries (10.4\%), hypertension $(9.4 \%)$, and previous decompression illness (8.5\%).

Table 4 shows a summary of the incidents occurring after the launch of the new medical system. Two occurred in divers with pre-existing medical conditions, but in neither case was the background condition likely to be related to the presentation of decompression illness. Both divers had been examined before the incident, and one had undergone investigation previously including echocardiography and exercise testing based on the questionnaire responses. Most incidents were caused by equipment failure or mistakes in diving practice.

Finally, fig 1 shows the time taken to respond to diver queries. The mean (SD) interval between receiving a form to sending an initial reply was 2.6 (3.2) days.

\section{DISCUSSION}

It is reassuring that the failure rate of divers has actually increased since the introduction of the new self certification system. Although divers were screened in the previous system by their general practitioners, it was very rare for a diver to be rejected outright by his/her own doctor, and referrals were usually made to the Scot-SAC medical advisor for a final decision to be made.

The number of divers declining assessment has also increased, and this is likely to be due to stricter enforcement of fitness to dive guidelines recommended by the UKSDMC. This includes treadmill tests and echocardiography in divers using $\beta$ blockers for the control of hypertension for example. Some divers are not prepared to undergo this investigation.

With the increased failure rate, it appears unlikely that the new system is failing to detect divers with significant medical conditions, and it is more appropriate now that divers are assessed by doctors with diving medicine experience.

The diving incident rate in Scot-SAC is low, and the pattern described is consistent with other studies showing that most incidents are due to either equipment failure or diving malpractice. $^{23}$ Incidents are often a chain of events, and although it is important to exclude medical conditions as the initial cause, it is also necessary to prove that such conditions do not impede a diver's response to a problem underwater.

The most common reason for assessment was asthma, and this was most commonly in relation to a childhood history of asthma. All divers with a history of asthma (however remote) are given information sheets explaining the risks involved

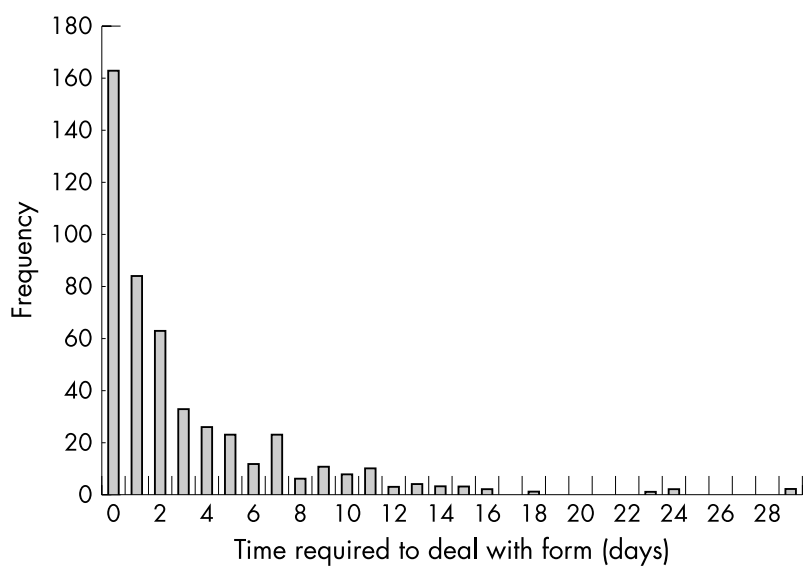

Figure 1 Time required for the initial response from medical referee after receiving referral from Scottish Sub-Aqua Club headquarters.

and, in particular, describing the possibility of pulmonary barotrauma (burst lung) caused by air becoming trapped during the ascent phase of diving. Divers are excluded if there is a history of asthma related to exercise, cold air, or emotional stress, and those with well controlled allergic asthma are required to monitor their peak flow rates throughout the diving season, as recommended by the UKSDMC medical standard. Airway stimulation testing such as saline or carbachol provocation is not performed routinely, because the prognostic importance of a positive result is uncertain, and the prevalence of positive results in normal subjects is also not known. This is a controversial area, however, and divers are made aware of the issues involved. The British Thoracic Society has recently introduced guidelines for the assessment of fitness to dive in respiratory conditions, and the UKSDMC medical standards are consistent with this. ${ }^{4}$

The new system has not led to delays in the certification of divers. In fact, the process appears to be efficient, with an initial response for most within two to three days. In many cases, it was possible to respond immediately, and communication was speeded by the use of email with due regard to medical confidentiality. The introduction of information sheets for common conditions such as asthma and hypertension ensures that all divers receive the same medical advice, and that investigations and restrictions are applied

Table 4 Incidents in the Scot-SAC population after the introduction of the new medical system

\begin{tabular}{|c|c|c|c|}
\hline Number & Type of incident & Medical background & Comment \\
\hline 1 & Possible neurological decompression illness & Hypertension & $\begin{array}{l}\text { Also stung by jellyfish; unclear if symptoms related to } \\
\text { this. No benefit from recompression }\end{array}$ \\
\hline 2 & Equipment failure & None & Shared ascent required after equipment failure \\
\hline 3 & $\begin{array}{l}\text { Failure to return to shore requiring lifeboat } \\
\text { assistance }\end{array}$ & None & Local weather conditions deteriorated \\
\hline 4 & $\begin{array}{l}\text { Arthralgia after diving holiday abroad with arm } \\
\text { paraesthesiae }\end{array}$ & None & $\begin{array}{l}\text { Required recompression; short dive to fly time } \\
\text { ( }<24 \text { hours) }\end{array}$ \\
\hline 5 & Arthralgia and subsequent arm paraesthesiae & None & Inadequate decompression; PFO screen negative \\
\hline 6 & Skin bend with non-provocative dive profile & None & Due for PFO screen \\
\hline 7 & Disorientation during wreck penetration & None & $\begin{array}{l}\text { Due to poor visibility; dive partner rescued without } \\
\text { mishap }\end{array}$ \\
\hline 8 & Neurological decompression illness & Hypertension and obesity & Excess diving before incident ( 18 dives in 9 days) \\
\hline 9 & Rapid ascent & None & Ran out of air (no consequences) \\
\hline 10 & Failure of surface cover & None & No consequences \\
\hline 11 & Neurological decompression illness & None & Erratic dive profile \\
\hline 12 & Arthralgia & None & Return journey involved driving at altitude $(1450 \mathrm{~m})$ \\
\hline 13 & Rapid ascent & None & Due to unfamiliarity with equipment \\
\hline 14 & Musculoskeletal pain after chamber dive & None & Not decompression illness \\
\hline 15 & Rapid ascent due to equipment failure & None & No medical consequences \\
\hline
\end{tabular}


uniformly. This is a concern in many countries where there can be considerable variability in how standards are applied. ${ }^{5}$

Scot-SAC is fortunate in being able to monitor the new medical system closely by retaining all records centrally. This also helps to control any confidentiality issues. It will be possible to continue long term evaluation of the medical system and the incident rates.

In summary, the introduction of a self administered questionnaire appears effective after three years of follow up, and there has been a reassuring increase in failure rates for divers, confirming the safety of the new screening system. Divers now have the benefit of direct assessment by doctors with diving medicine experience.

\section{ACKNOWLEDGEMENTS}

I gratefully acknowledge the invaluable assistance of Alicia Bannon, the Scot-SAC administrator, and the National Diving Officers during the study (Ian Seath, Gus Furrie, and Robert Ronaldson). The UKSDMC members involved in designing the self administered questionnaire were Drs Sandra Domizio, John Betts, Phil Bryson, Chris Edge, Pat Farrell, David Lindsay, Mike O'Kane, and Peter Wilmshurst. Feedback on the UKSDMC questionnaire was also received from Lizzie Bird (British Sub-Aqua Club National Diving Officer), Paul Johnson-Ross (Sub-Aqua Association National Diving Officer), and Professor David Elliott OBE.

Conflict of interest: none declared

\section{REFERENCES}

1 Glen S, White S, Douglas J. Medical supervision of sport diving in Scotland: reassessing the need for routine medical examinations. Br J Sports Med 2000;34:375-8.

2 Anon. DAN 1998 report on diving accidents and fatalities. Durham, NC: Divers Alert Network, 1998.

3 Cumming B. NDC Diving Incidents Report 2002. British Sub-Aqua Club, Telford's Quay, Ellesmere Port, South Wirral, Cheshire CH65 4FL.

4 Godden D, Currie G, Denison D, et al. British Thoracic Society guidelines on respiratory aspects of fitness for diving. Thorax 2003;58:3-13.

5 Simpson G, Roomes D. SCUBA diving medical examinations in practice: a postal survey. Med J Aust 1999;171:595-8.

\section{ELECTRONIC PAGES}

\section{Online case reports}

7

he following electronic only articles are published in conjunction with this issue of BJSM (see also pages 724,

742 , and 753).

Endurance exercise and the production of the vascular endothelial growth factor and haematopoietic factors in patients with anaemia

F Dimeo, W Knauf, D Geilhaupt, et al

Background: Physical activity has been shown to stimulate haematopoiesis in patients with anaemia due to chronic renal failure or haematological malignancies.

Objective: To evaluate the effect of moderate exercise on the production, release, and reuptake of haematopoietically active factors.

Methods: Ten patients (four men and six women, mean (SD) age 51 (10) years) with a haemoglobin concentration under $130 \mathrm{~g} / \mathrm{l}$ (men) or $120 \mathrm{~g} / \mathrm{l}$ (women) carried out five three minute exercise bouts at an intensity of $80 \%$ of the maximal heart rate, corresponding to a lactate concentration of $3(0.5)$ $\mathrm{mmol} / \mathrm{l}$. Patients rested for three minutes between bouts. The concentrations of interleukin 6, stem cell factor, granulocytemonocyte colony stimulating factor, granulocyte colony stimulating factor, erythropoietin, and growth hormone $(\mathrm{GH})$ were evaluated before and in the eight hours after exercise.
Results: GH had risen significantly 15 minutes after exercise (1.1 (1.3) v 2.7 (2.8) ng/ml; p,0.05). No change in the concentration of the other cytokines and growth factors was observed in the eight hours after exercise.

Conclusions: In patients with anaemia, submaximal exercise does not affect the concentration of haematopoietically active cytokines. However, it leads to an increased concentration of GH. This may be responsible for the improved haematopoiesis observed after an exercise programme in patients with chronic diseases.

(Br J Sports Med 2004;38:e37) http://bjsm.bmjjournals.com/ cgi/content/full/38/5/e37

Soleus accessorius, an anomalous muscle in a young athlete: case report and analysis of the literature A Christodoulou, I Terzidis, K Natsis, et al

The soleus accessory muscle is a rare anatomical variation. It usually appears as a soft tissue mass and may be mistaken for a tumour or an inflammatory lesion. The differential diagnoses include ganglion, lipoma, haemangioma, synovioma, and sarcoma. This is a report of such a muscle mass in the leg of a young athlete with 16 years follow up. A review of the English literature on this subject is also presented.

(Br J Sports Med 2004;38:e38) http://bjsm.bmjjournals.com/ cgi/content/full/38/5/e38 